\begin{tabular}{|c|c|c|}
\hline & $\begin{array}{c}\text { Port Said Engineering Research Journal } \\
\text { Faculty of Engineering - Port Said University } \\
\text { Volume 16 No. } 2 \text { pp.: 54:60 }\end{array}$ \\
\hline
\end{tabular}

\title{
PRELIMINARY ESTIMATION OF THE PRINCIPAL DIMENSIONS OF OFFSHORE SUPPLY VESSEL BASED ON UPDATED STATISTICS
}

\author{
MOHAMED WALID AHMED*, AHMED NAGUIB ** and ELSAYED H. HEGZY*** \\ *Lecturer, Marine Engineering Technology Department, Faculty of Maritime Transport, Arab Academy for Science, Technology and Maritime Transport \\ (AASTMT). Alexandria, Egypt, mohamed_walid5@yahoo.com \\ ** Lecturer, Marine Engineering Department, Faculty of Engineering, Arab Academy for Science \& Technology and Maritime Transport (AASTMT). \\ Alexandria, Egypt, anaguibamd@yahoo.com \\ ***Professor of ship structural design, Faculty of Engineering, Port Said University, dr_elsayed_hegazy@yahoo.com
}

\begin{abstract}
There are many formulae for estimating the principal dimensions of OSVs (offshore supply vessels) depending on previous data of existing ships. Some formulae are not suitable for modern design, because of the great development in ship engineering. Therefore, it was necessary to get new formulae to estimate the principal dimensions of OSVs. The aim of this paper is to introduce and update the data that can be used to quickly predict the main dimensions of OSVs in preliminary (basic/pre-contract) design stage. For this purpose, data from statistical survey of 80 existing modern OSVs have been reviewed and reintroduced in the form of charts and equations. Finally, it has to be noted that these charts and equations need to be updated from time to time to cope with the continuous developments in the industry of OSVs . The obtained results were compared with previous formulae, and it was found that the obtained results are closer to the existing unit particulars.
\end{abstract}

\section{Introduction}

The OSVs (offshore supply vessels) are used in general to supply services for all kinds of platforms and offshore rigs, transporting wet drilling fluids, acids and chemicals and dry bulk in addition to deck cargo. The vessels' hull and propulsion engine capacities kept increasing gradually as drilling and production activity moved into deeper waters. In order to offer a safe and efficient anchor handling operation in deep water conditions in excess of 2000 meters, various design changes were necessary.

OSVs are generally wide beamed in comparison with conventional cargo vessels. They are usually constructed as a flat cargo deck aft positioned on top of a collection of cargo tanks surrounding the machinery spaces. The accommodation is forward surmounted by a wheelhouse designed for excellent all round visibility. These vessels have duplicate navigational controls at both the forward and aft ends that on modern vessels are ergonomically designed. Most of the vessels are extremely maneuverable.

\section{Features of offshore supply vessel}

One or more of the following design and operating features can generally be expected for OSVs.
- Large and open aft deck for cargo, equipment, anchors handling and towing operations.

- Stern roll for anchor handling

- Wheel house all - round visibility( have forward $\&$ aft control)

- Some OSVs equipped with A-frame to reduce the tension of wire.

- High engine power for towing operations.

- High maneuverability, particularly at low speed or static operation. (Bow and stern thrusters).

- Propeller types (fixed or variable pitch with Kort nozzle, Voith Schnieder, Azimth and Azipod propeller)

- Storage of consumables for offshore exploration and production activities: such as drilling fluids, bulk mud and cement, water, fuel, chemicals, etc.

- Some OSVs are equipped with big fire pump with monitors for external fire fighting system.

- Now Dynamic Positioning (DP) system is very important for all types of OSVs.

A typical general arrangement of OSVs is shown in figure 1. 


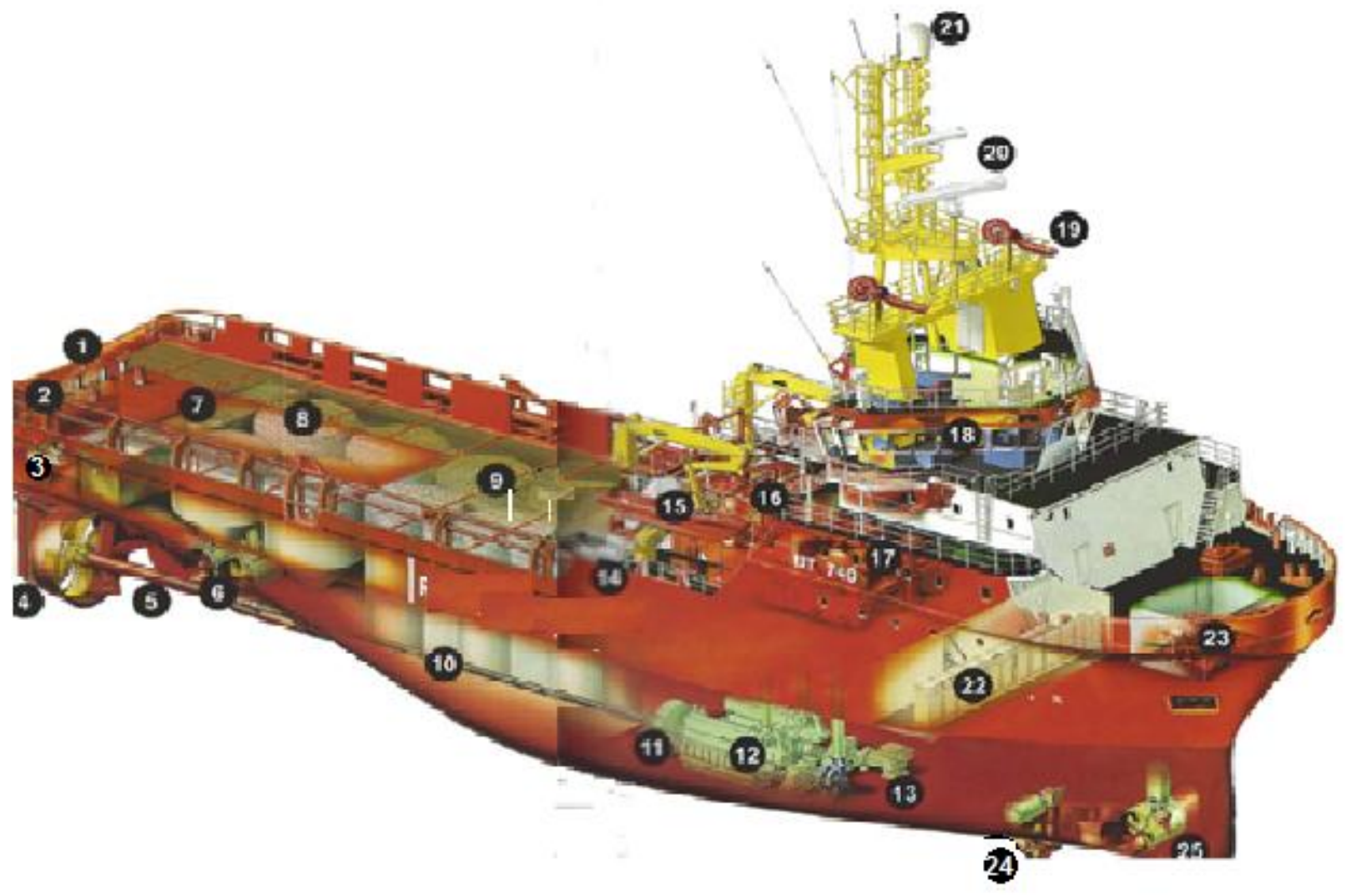

Fig 1 Anchor handling and towing vessel [1]

1. Stern roll for anchor handling

2. Stopper for anchor handling

3. Steering engine

4. Starboard ducted propeller

5. Stern tube

6. Transverse thruster gear and ship steering

7. Cofferdam

8. Tanks for dry bulk cargo (Cement)

9. Mud tanks

10. Propeller shaft

11. (Reduction) gear box

12. Main engine

13. Fire pump

14. Life raft

As exploration and production activities move into deeper waters, a certain shift in the basic design in offshore supply vessel is evident. Just on drilling operations alone, more cargoes in terms of hardware such as drill pipes on the one hand, to consumables such as drilling fluids on the other, have to be supplied per trip than for shallow water activities. Deepwater also mean further away from shore base, this means the need for higher speed. Deployment and retrieval of anchors of
15. $\mathrm{MOB}$ - boat with crane

16. storage reel for steel wires for anchor handling

17. anchor handling winch

18. bridge with controls for deck

19. fire fighting monitor

20. Rader antennas

21. Antenna for communication system / satellite antenna

22. Watertight bulkhead

23. Watertight bulkhead

24. Azimuth thruster

25. Bow thruster

various types in deep waters need more powerful winches than for shallow water .[2]

In addition to these challenges, the modern OSVs may be equipped for emergency responses such as fire fighting,

Standby operation, rescue and anti-pollution according to the required degree. 


\section{Design Aspect}

The first problem that a naval architect faces when he starts to design a ship is the selection of main dimensions suitable for the new design meeting all the specified requirements. The requirements of dead-weight or capacity, speed and ranges, cargo handling facilities and dimensional limitations have to be stated.

From the view point of shipyard's naval architect these may come as specified requirements, but for an owner's naval architect or for a consultant, establishing these is the first stage in design. However well design meets a set of requirements, it may result in an unsuccessful ship if these have not been well selected. [3]

The main dimensions decide many of the ship's characteristics, e.g. stability, tank capacity, power requirements, and even economic efficiency. Therefore determining the main dimensions and form ratios represent an important phase in the overall design of a ship. [4]

The first step in the preliminary design is to estimate the lightweight of the new ship. This can be done by knowing the deadweight coefficient which is the ratio between deadweight and displacement. The deadweight coefficient for OSV has an approximate value of 0.52 . [5]

The second step in preliminary design stage is to estimate the length of the new required ship. Usually, the length is determined from similar ships or from formulae and diagrams (derived from a database of similar ships). The resulting length then provides the basis for finding the other main dimensions. There are many traditional formulae to determine the length of a new ship, namely: Ayer's formula, Posdunine's formula and Cube Root format. [4]

1- Ship's length recommended by Ayre : [4].

$$
\frac{\mathrm{L}}{\nabla^{1 / 3}}=3.33+1.67 \frac{\mathrm{V}}{\sqrt{\mathrm{L}}}
$$

2- $\quad$ Posdunine Formula [16].

$$
\mathbf{L}=\mathbf{C}\left(\frac{\mathrm{V}}{\mathrm{V}+2}\right)^{2} \Delta^{1 / 3}
$$

$$
\text { C coefficient }=1.7 \frac{\mathrm{V}}{\sqrt{\mathrm{L}}}+4.4
$$

Cube root format from information on ships already built and in service, the naval architect can decide upon the relationships of $\mathrm{L} / \mathrm{B}$ and $\mathrm{B} / \mathrm{T}$ for the new ship .Knowing these values the designer can have a good first attempt for the main dimensions for the new vessel. He can use the following formula: [5]

$$
\mathbf{L}=\left(\frac{D W T \times(L / B)^{2} \times(B / T)}{\rho \times C_{b} \times C_{D}}\right)^{\mathbf{1 / 3}} \mathbf{~ m ~ \ldots ( 3 )}
$$

Where:

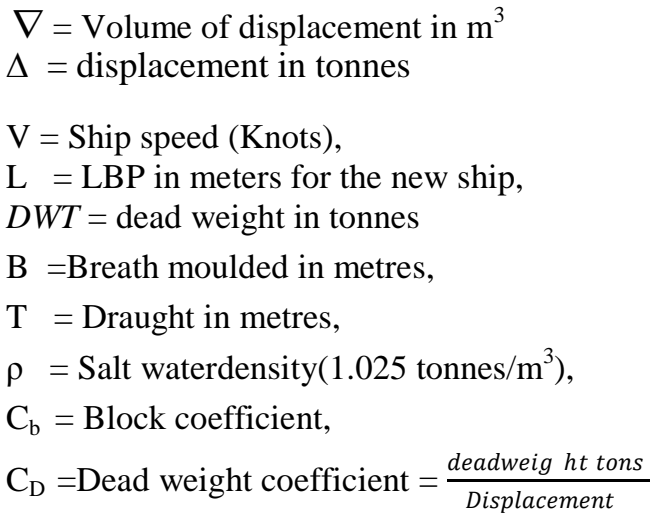

\section{Proposed Formula for OSVs Length}

It is difficult to say that the lengths determined for ships using Ayer's formula (1949) or Völker's Formula(1974) or Cube Root Format (2004) are still valid as technology and economy have been remarkably changed in the last decades. Therefore it is necessary to obtain such formulae based on recent data for existing OSVs. This job was done in this paper for the purpose of picking up new formulae for determining the length as well as other main dimensions for OSVs.

For this purpose, the main particulars of 80 OSVs were collected from local and international companies built from 1983 to 2011. By reviewing data, it is found that. the dimensions of OSVs were increased due to increase of the dead weight. These dimensions include the length between perpendicular from $40 \mathrm{~m}$ in up to $80 \mathrm{~m}$, the breadth from $10 \mathrm{~m}$ up to $22 \mathrm{~m}$ and the draught from $4 \mathrm{~m}$ up to $7.8 \mathrm{~m}$. Also, the engine power were raised from $4000 \mathrm{hp}$ to $2900 \mathrm{hp}$ due to increase of towing and anchor handling operations in deep sea.

From such data Figure (2) was drawn which shows the relationship between the lengths of OSVs and the dead weights. From these results equation (4) was derived for determining the length between perpendiculars (LBP) of OSVs.

$$
\mathrm{L}_{\mathrm{BP}}=\mathbf{6 . 5 3 1 6} \text { (DWT) }{ }^{\mathbf{0 . 2 9 7 5}}
$$

This formula is applicable for OSVs with $800 \leq \mathrm{DWT} \leq$ 5000 tones.

Where:

$\mathrm{L}_{\mathrm{BP}}$ is the length between perpendiculars (m)

DWT $=$ deadweight (tones) 


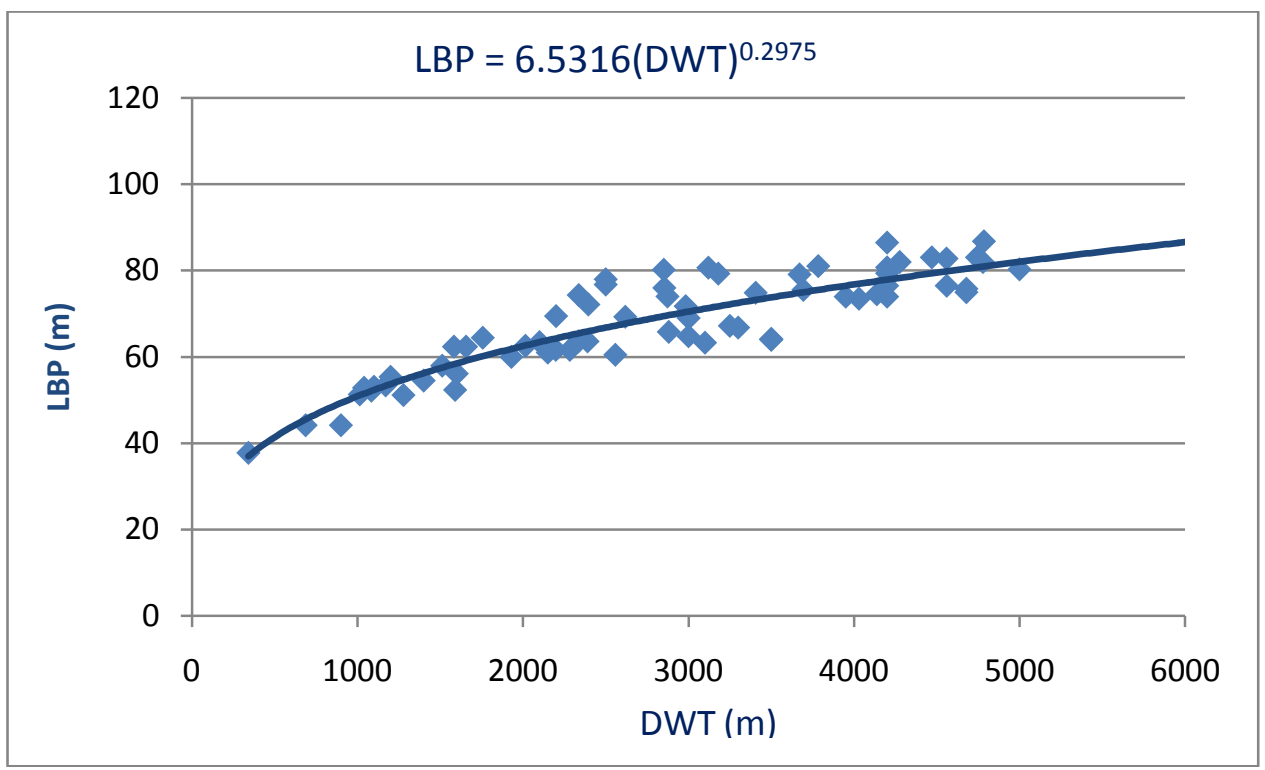

Fig (2) Length between perpendiculars and Dead weight relationship

\section{Comparison between Different} Formulae for Determining the Length of OSVs.

Table (1) shows comparison between the length calculated by previous methods (see equations 1,2,3) as well as by the proposed formula equation(4) and the actual length .

Table (1) comparison between actual length and calculated lengths by different methods

\begin{tabular}{|c|c|c|c|c|c|c|c|c|c|c|c|}
\hline $\begin{array}{l}\text { Ship's } \\
\text { name }\end{array}$ & $\begin{array}{c}\text { Building } \\
\text { date }\end{array}$ & DWT & $\begin{array}{l}\text { Actaul } \\
\text { L(m) }\end{array}$ & \multicolumn{2}{|c|}{$\begin{array}{l}\text { Ayre's } \\
\text { L(m) }\end{array}$} & \multicolumn{2}{|c|}{$\begin{array}{c}\text { Posdunine s } \\
\text { L(m) }\end{array}$} & \multicolumn{2}{|c|}{$\begin{array}{c}\begin{array}{c}\text { cube root } \\
\text { format }\end{array} \\
\mathbf{L}(\mathbf{m})\end{array}$} & \multicolumn{2}{|c|}{$\begin{array}{c}\begin{array}{c}\text { proposed } \\
\text { method }\end{array} \\
\mathbf{L}(\mathbf{m})\end{array}$} \\
\hline vos hecate & 2010 & 1360 & 54 & 71.7 & $32.7 \%$ & 64.3 & $19.1 \%$ & 57.16 & $5.8 \%$ & 55.88 & $3.4 \%$ \\
\hline$P S V 22$ & 2010 & 2590 & 68.88 & 86.9 & $26.1 \%$ & 78.2 & $13.5 \%$ & 70.9 & $2.9 \%$ & 67.68 & $-1.7 \%$ \\
\hline $\begin{array}{c}\text { Bourbon } \\
\text { horus }\end{array}$ & 2009 & 2890 & 69 & 88.58 & $28.3 \%$ & 79.7 & $15.5 \%$ & 73.5 & $6.5 \%$ & 69.92 & $1.33 \%$ \\
\hline UT $755 \mathrm{LN}$ & 2009 & 3270 & 68.3 & 95 & $39 \%$ & 86.9 & $27.2 \%$ & 76.5 & $12 \%$ & 72.54 & $6.2 \%$ \\
\hline $\begin{array}{c}\text { OLYMPIC } \\
\text { ZEUS }\end{array}$ & 2009 & 4931 & 82.7 & 106.3 & $28.5 \%$ & 97.3 & $17.7 \%$ & 87.8 & $6.1 \%$ & 81.97 & $-0.9 \%$ \\
\hline МMC887 & 2008 & 5145 & 83 & 108.3 & $30.1 \%$ & 99 & $19.3 \%$ & 89,08 & $7.3 \%$ & 83.01 & $0.01 \%$ \\
\hline
\end{tabular}

In a similar way as obtained for vessels 's length ,the following proposed formulae were obtained from analyzing the curves shown in figure (3) to estimate the breadth, depth and draught of OSVs

\section{Preliminary Estimation of Other Main Dimensions of OSVs.}

From the figure (2), it is clear that the length calculated by proposed method has the least deviation 


$$
\mathrm{T}=0.6927(\mathrm{DWT})^{0.274}
$$

as functions of the required dead weight (DWTs), respectively:

$$
\begin{aligned}
& \mathrm{B}=1.719(\mathrm{DWT})^{0.2903} \\
& \mathrm{D}=0.856(\mathrm{DWT})^{0.271}
\end{aligned}
$$

Where:

$$
\begin{aligned}
& \mathrm{B}=\text { Breadth in }(\mathrm{m}), \\
& \mathrm{D}=\text { Depth in }(\mathrm{m}), \\
& \mathrm{T}=\text { Draught in }(\mathrm{m}),
\end{aligned}
$$

DWT $=$ Deadweight in (tonnes).

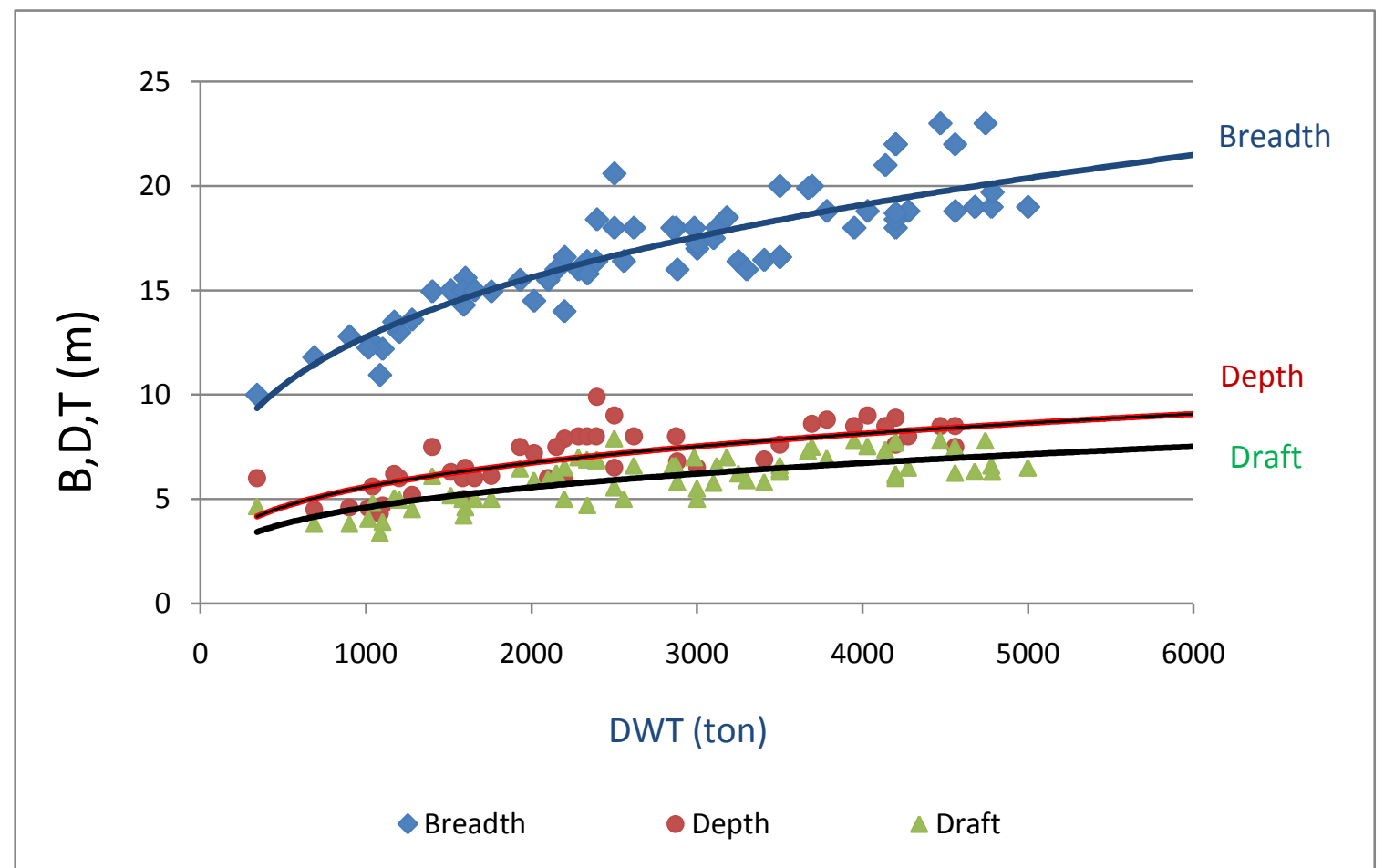

Figure (3) Breadth, depth, draught and dead weight relationship

\section{Comparison between Proposed Formulae and actual value of breadth, depth and draught for OSVs.}

figures 4,5and 6 show the proposed methods and the actual values of breadth, depth and draught for existing OSVs, respectively. 


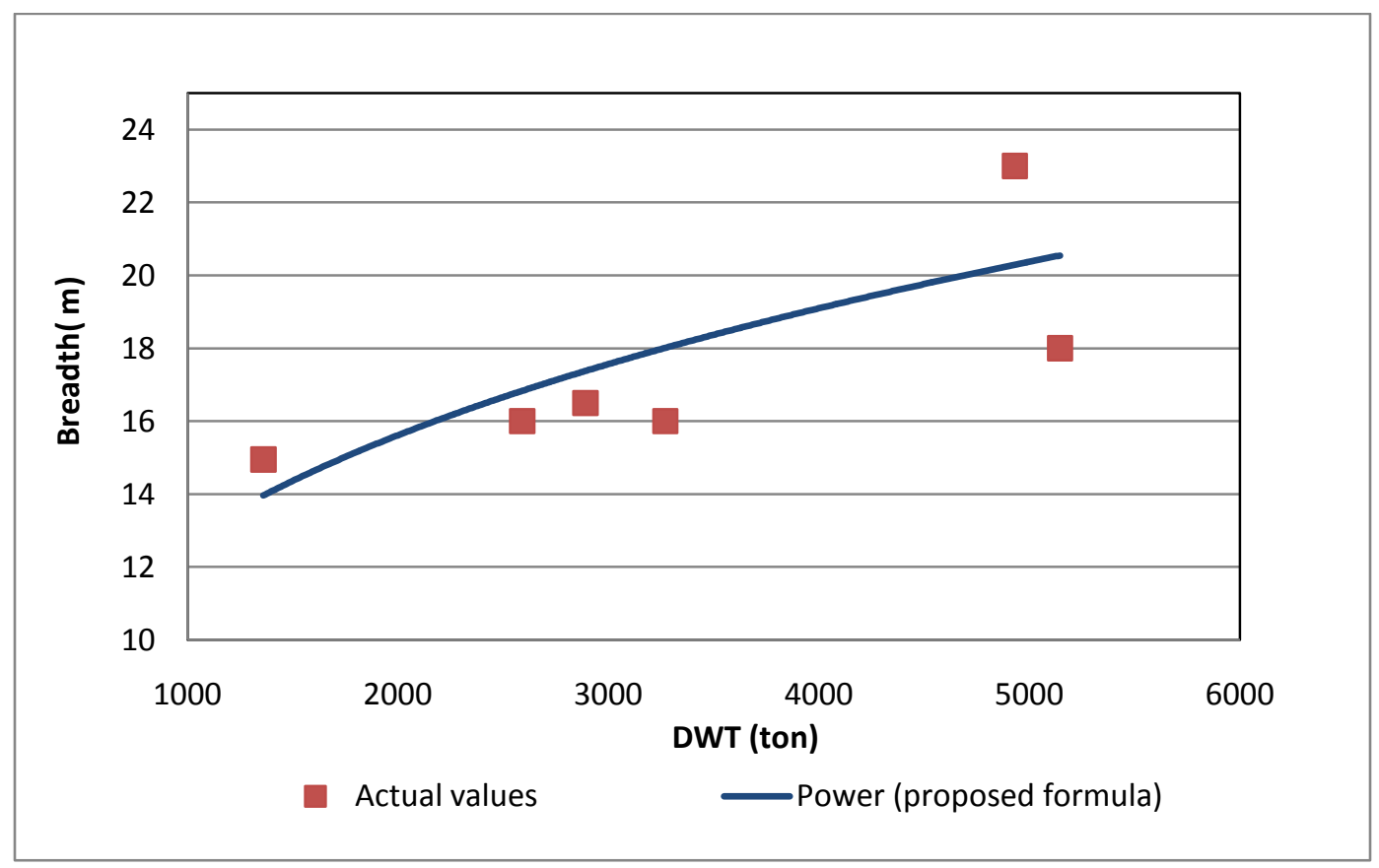

Figure (4) Comparison between breadth as calculated by proposed formula and actual breadth

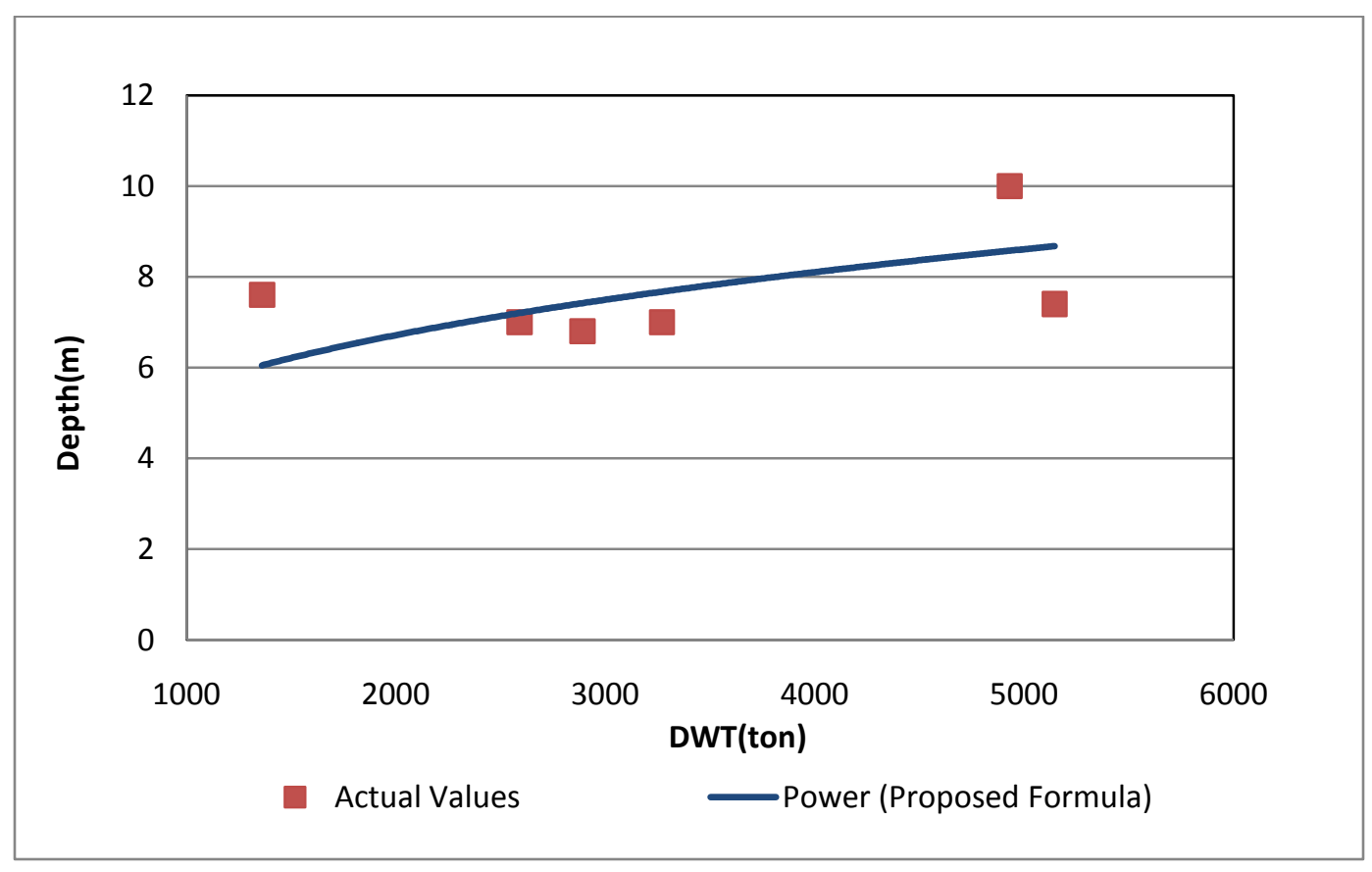

Figure (5) Comparison between depth as calculated by proposed formula and actual depth 


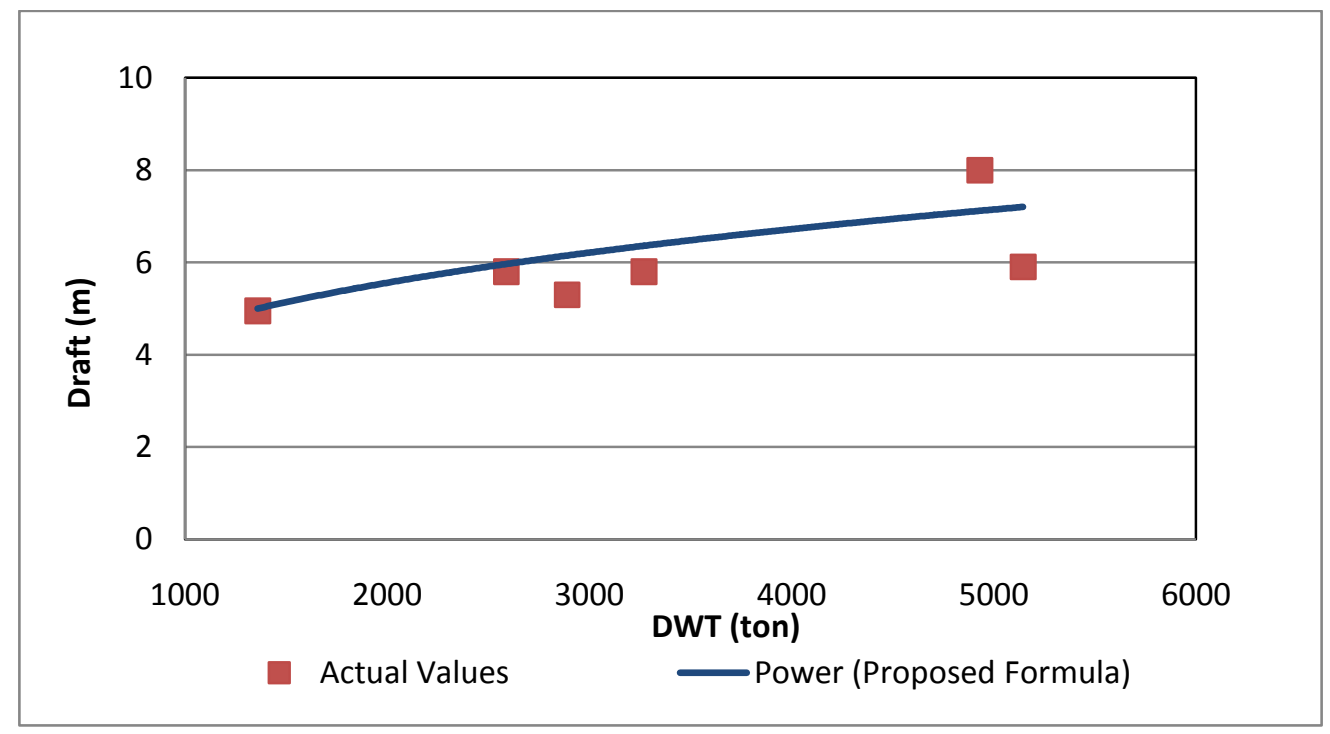

Figure (6) Comparison between draught as calculated by proposed formula and actual draught

\section{Conclusion}

The main dimensions decide many of ship's characteristics, e.g., stability, tanks capacity, power requirement, and even economic efficiency. Therefore estimating the main dimensions is a particularly important phase in the overall design procedure of a new ship especially in preliminary design stage to identify the main features of the ship. A quick and simple method based on statistical analysis of the data of modern 80 existing OSVs of different sizes has been proposed and represented in simple formulae and graphs ready for use to estimate length, breadth, depth and draught in preliminary design stage for OSVs. The length of OSVs calculated by the proposed formula was compared with the result of previous formula; the comparison showed that the length estimated by Ayre , Posdunine and Cube root format formulae were far beyond than the actual length. These differences are due to the change of lengths of recently built vessels with higher maneuverability. while, the proposed formula shows quiet close value to actual length. The values of proposed formulae of other main dimensions (breadth, depth, draught) were also in good agreement with the actual values.

\section{References}

[1] VAN DOKKUM. K, (2003), Ship knowledge A modern encyclopedia. The Netherlands: MEPPEL.

[2] Offshore Magazine, August (2004), Anniversary Special: 50 key events, technologies shaped the offshore industry

[3] Watson, David G.M. (1998), Practical Ship Design. volume1, Amsterdam: ELSIVER.
[4] Schneekluth \& V. Bertram (1998), Ship Design for Efficiency and Economy second edition, Oxford: Butterworth-Heinemann

[5] BARRAS (2004), Ship Design and Performance for Master and Mates. Amsterdam: ELSIVER.

[6] ILL., International Convention on Load Line(1966/88), International Maritime, Organization 1966/88.

[7] MARPOL, International Convention for the Pollution Prevention1973/1978 from Ships, International Maritime Organization.

Collected data from internet sites:

[9] Available from :http://www.abb.com/marine "Accessed, May 2011",

[10]Available from: http://www.bourbon-online. com "Accessed, June 2011",

[11]Available from: http://www. harveygulf. com/pdf lexplorer.pd"Accessed, May 2011",

[12] Available from: http://www. siemoffshore. Com" Accessed, April 2011",

[13]Available from: http:// www.stxeurope .com" Accessed, May 2011",

[14] Available from: $\underline{\text { http:// }}$ www.ulsteingroup.com"Accessed, July 2011",

[15] Available from: http:// www.er-ship.com" Accessed, July 2011",

[16] Available from: www. Scribd .com /doc /7109606/Empirical-Formula 